1

\title{
Screening for Opportunistic Intestinal Parasites in HIV/AIDS Patients, Attending the Services of Medical Care in Three Different Hospitals, Southern Ethiopia
}

Feleke Eriso

Department of Biology, College of Natural and Computational Sciences, Dilla University, Dilla, Ethiopia

Corresponding Author: Feleke Eriso

Mobile:

$+251916514682$

E mail:

feleke.eriso@yahoo. com

Key words: HIV/AIDS, hospital, morbidity, opportunistic, mortality, patients, parasites
Background and study aim: Diagnostic examination of stools for opportunistic intestinal parasites in HIV/AIDS patients is given less attention than it should be. The suspected opportunistic intestinal parasites such as Cryptosporidium parvum, Cyclospora cayentanensis, Toxoplasma gondii, Isospora belli and the symptom of explosive watery diarrhea they cause as well as others including Strongyloides stercoralis are the threat against the well-being of HIV/AIDS patients. The objective of this study is to demonstrate the indispensable necessity to free HIV/AIDS patients (who are under medical care in 3 different hospitals, Southern Ethiopia), from opportunistic intestinal parasites using diagnostic examination of stools followed by prompt curative treatment during every safety time interval.

Patients and methods: Fresh stools samples from a total sample size of 710 HIV/AIDS patients were taken and examined in the parasitology laboratory, Dilla University, for the suspected intestinal opportunistic parasites. The methods employed to identify the intestinal parasites included observations in : wet mount, formalin-ether concentration technique, and permanent

\section{INTRODUCTION}

Diagnostic examination of stools for opportunistic intestinal parasites in HIV/AIDS patients is of great validity in providing the service of prompt curative treatment so as to safe guard the patients against chronic morbidity [1-9]. The curative treatment of the opportunistic intestinal infections does get control of the present infection (illness) but cannot prevent the possibility of reinfection. Even after the regular administration of free Anti-Retroviral Therapy (ART) in short slide preparation as well as Baermann apparatus method for Strongyloides stercoralis.

Result: Out of 710 HIV/AIDS patients examined 196 were found to be positive for 6 different species of the suspected intestinal parasites (infection rate of these parasites in the population of HIV/AIDS patients of the 3 different hospitals being

$$
\frac{196}{710} \times 100=27.6 \%
$$

The six species of parasites isolated from fresh stools samples were: Ascaris lumbricoides, Strongyloides stercoralis, Entameba histolytica, Giardia lamblia, Balantidium coli, and Trichuris trichiura. Conclusion: Reasonably planned successive safety time intervals must be attended continuously by HIV/AIDS patients without interruption to utilize the services of medical care in order to avoid/ neutralize the potential opportunistic infections and reinfections; otherwise, the fulminant death can turn to be true. The safety and well-being of those HIVinfected patients who attend all the medical services \& advices provided by clinical experts is not different from that of HIV-noninfected individuals without any trace of exaggeration.

intervals of time, opportunistic intestinal parasites cannot be ignored. Therefore, the HIV-infected individuals should be screened for opportunistic intestinal parasites within reasonably safe intervals of time by way of diagnostic examination of stools [10-20]. After 30 years of HIV epidemic, parasites have become one of the most common opportunistic infections and one of the most important causes of morbidity and mortality against the well-being of HIV-infected individuals [21-23]. 
Screening for intestinal parasites followed by quick curative treatment or prevention of harmful infections improves the safety and duration of life of the HIV-infected persons [24,25]. The prevalence of harmful intestinal helminth infections in asymptomatic HIV- infected individuals has been identified and with this truth in mind screening HIV-infected patients for opportunistic intestinal parasites cannot be ignored by any means [26-30]. The HIV/AIDS epidemic so compromises the immune system of its victims that they are left virtually defenseless. Even relatively benign parasites that cause only mild symptoms, in a healthy person, can be quite devastating to a patient suffering from AIDS [31-35]. The suspected opportunistic intestinal parasites such as Cryptosporidium parvum, Cyclospora cayentanensis, Toxoplasma gondii and Isospora belli with their symptom of explosive watery diarrhea and others including Strongyloides stercoralis are the threat against the well-being of HIV/AIDS patients.

The purpose/objective of this study is to demonstrate the indispensable necessity to free HIV/AIDS patients (who are under medical care in 3 different hospitals found in Southern Ethiopia), from opportunistic intestinal parasites using diagnostic examination of fresh stools followed by prompt curative treatments during every successive safety time interval. Here, the objective means that if the HIV-infected patient is found to be positive for one or more species of the suspected intestinal parasites he/she will be given the best choice of treatment quickly and cured. However, it cannot promise/guarantee that other parasitic infections or reinfections with the same species of parasite/s do not occur until the end of the next (subsequent) safety time interval. But if the suspected parasitic infections occur within this length of reasonably predetermined time interval, it is very likely that the opportunistic parasites cannot overpower (i.e., they cannot build up resistance against) promptly successful curative treatment.

\section{PATIENTS AND METHODS}

Three different hospitals were the sites of sample taking. The 3 different hospitals where the HIV/AIDS patients had been under medical care were:

-Dilla University, Teaching and Referral Hospital,

- Yirgalem General Hospital, and

- Yirgacheffe Health Center.

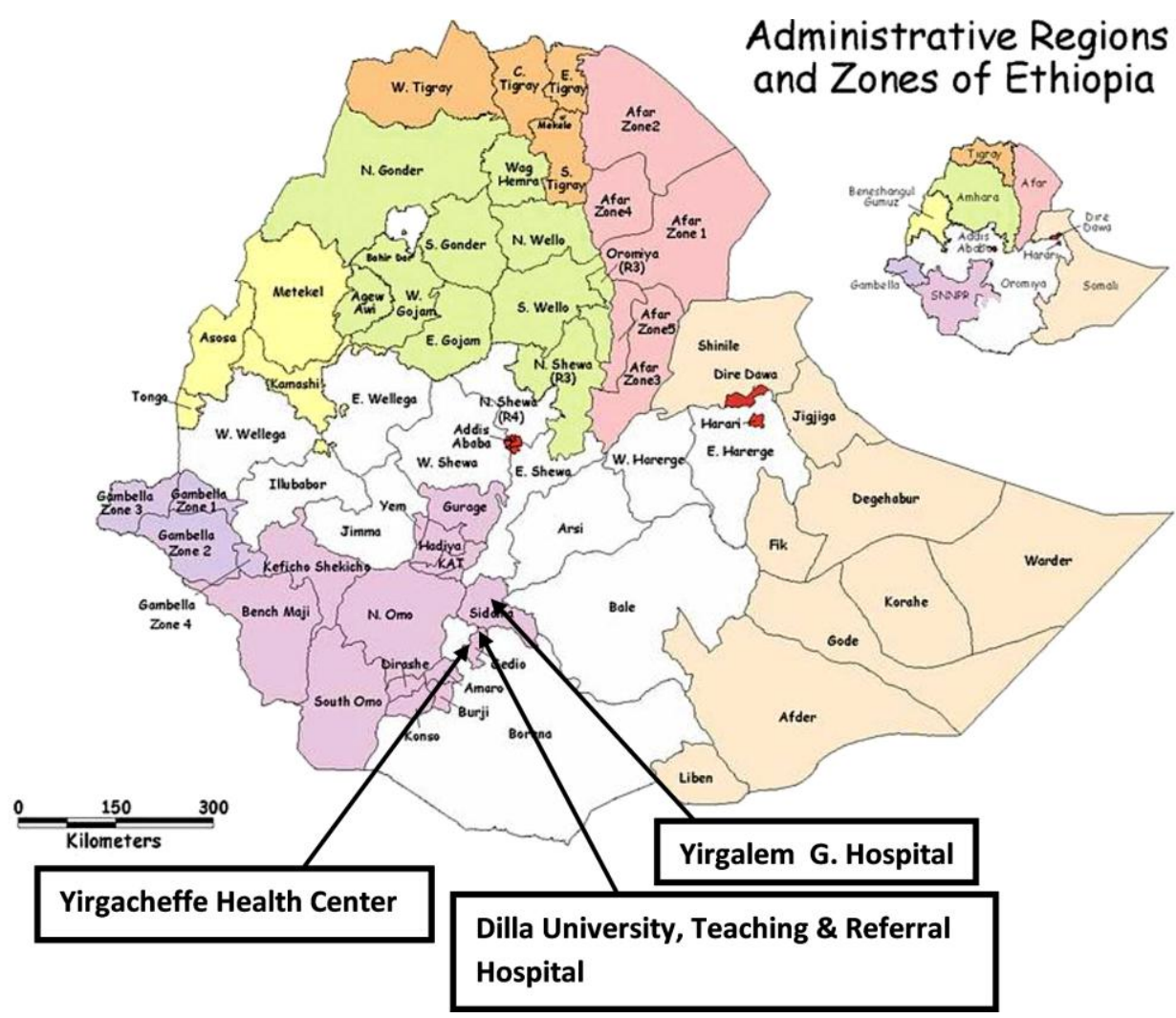

Figure (1): Map of Ethiopia to show the locations of the 3 different hospitals where the HIV/AIDS patients were under medical care. 
The total sample size of 710 HIV/AIDS patients was decided to be examined for the suspected harmful intestinal parasites of man. The samples taken from HIV infected patients of the hospitals cited above were fresh stools. Collection of stools samples from the hospitals and documenting the findings had been carried out daily, Monday through Friday (i.e., every week) from October 2013 to June 2014. The statistics selected, being relevant to interpret and analyze the results of this study were percentage and histogram. The fresh stools sample of each HIV/AIDS patient was examined with a compound light microscope at three stages:

- Direct wet mount,

- Concentration technique, and

-Permanent staining.

\section{Procedure}

Direct wet mount:

- About $2.5 \mathrm{ml}$ of fresh stools sample was taken in a small vial from each HIV/AIDS patient of the hospitals selected. Immediately after that, $0.85 \%$ $\mathrm{NaCl}$ solution in distilled water and warmed to $370^{\circ} \mathrm{C}$ was added to each vial of fresh stools sample taken. Then 1 drop of $0.85 \%$ warm $\left(370^{\circ} \mathrm{C}\right)$ aqueous $\mathrm{NaCl}$ (saline solution) was placed on a clean slide.

- Following that, about 1 drop of the stools specimen (from that of any single HIV/AIDS patient) was added to the slide and mixed with the drop of $\mathrm{NaCl}$ solution.

- The saline wet mount was covered with a cover slip and examined under a suitable objective lens. This procedure of using warm saline solution was to allow determining the motility and gross morphology of trophozoites. In the mean time, care was taken not to allow the sample on the slide to dry or cool; otherwise, the motility of trophozoites could have ceased. The stools specimen of any particular HIV/AIDS patient who was positive for the suspected parasites was preserved in 5\% formalin (for protozoans) or in $10 \%$ formalin (for nonprotozoan parasites) to be used in the stages of Concentration Technique and examination of Permanent Staining Preparation. The stools specimen of each patient was prepared, observed, and preserved exactly in this way.

\section{Concentration technique:}

-Involved concentrating the number of the diagnostic stages of the suspected parasites, primarily of cysts, eggs or larvae in the stools specimen that was collected and preserved in $5 \%$ or $10 \%$ formalin. These concentrated and preserved specimens were part of the complete examination and the detection of small numbers of the parasites that could have been difficult. In order to concentrate the number of the diagnostic stages of the parasites, diethyl-ether had been mixed with the suspension of the stools sample. Then, the speed and concentration time were set at $1000 \mathrm{rpm}$ for 2 minutes.

- Next, the parasites particularly the cysts, eggs, or larvae were expected to sediment at the bottom of the centrifuge tube and the floating stools debris was discarded.

\section{Examination of permanent staining preparation:}

-Detection and identification of intestinal protozoan and helminth parasites preserved in $5 \%$ or $10 \%$ formalin respectively would be enhanced by the examination of permanently stained smears under the oil immersion objective lens.

- These stained slides would provide a permanent record of the suspected intestinal parasites of man.

- The identifications in the stages (steps) of Direct Wet Mount and Concentration Technique would be reconfirmed by the permanently stained slide.

-The staining was with Safranin. Safranin is a stain used in histology to stain tissues and to stain gram-negative bacteria as a counterstain. Safranin is not known at all to stain protozoa or any other parasite here before. When it was tried to stain the worms of $S$. stercoralis, for the first time, it gave a very good dyeing effect. It stained the worms red. It also stains well the cysts of E. histolytica, G. lamblia, and nearly all other diagnostic stages of human intestinal parasites. This is an unexpected advantage as it increases the spectrum of options in techniques of staining.

- About 3 drops of Safranin solution was added to the stools specimen suspension preserved in formalin in a bottle of about $50 \mathrm{ml}$ and waited for about 6 hours to get the diagnostic stages of the parasites stained.

- A drop of Yetwin Mounting Medium melted at $650^{\circ} \mathrm{C}$ was placed on a clean slide, then on this drop of mounting medium, a drop of the stools specimen preserved in formalin and stained with Safranin was added and mixed well with the tip of a needle. Next, the specimen was covered with a coverslip and left on a table for 
about 24 hours to let the mounting medium solidify and harden.

- Thereafter, the specimen in the hardened mounting medium was examined under the oil immersion objective lens to check the presence of the suspected intestinal parasites of man.

\section{Additional methods:}

- Baermann apparatus technique was employed for the diagnostic tests of $S$. stercoralis. Here, the Low or Middle Power objective lens was used in observing under the compound light microscope.

-In all methods of this paper, from all fields of vision (i.e., low power to oil immersion) of the microscope, microphotographs of the parasites diagnosed were taken using a digital camera and transferred to computer for further processing.

\section{Treatment}

Curative drugs of choice were used against $E$. histolytica, G. lamblia, and B. coli. Albendazole was the drug available to neutralize the infections with $S$. stercoralis and other helminths.

\section{RESULTS}

A horrifying death of a 26 years old HIV/AIDS patient with exhaustive watery diarrhea has been recorded. Another 13 years old male HIV/AIDS patient has also been observed to be threatened by watery diarrhea. Out of 710 HIV/AIDS patients examined for the suspected harmful intestinal parasites, 196 patients were found to harbor six different species of parasites.

There were 11 HIV/AIDS patients with multiple infections. Each of these 11 patients were identified to harbor two different species of intestinal parasites. For instance, the 26 years old HIVinfected lady who died in a terrifying situation because of her own carelessness to attend the services of medical care \& advices provided by medical experts in the hospital, was infected by two intestinal parasites, namely: Balantidium coli, and Trichuris trichiura. The 13 years old HIVpositive child who had been challenged by watery diarrhea and cured by a quick curative treatment was also infected by two intestinal parasites; i.e., Balantidium coli and Entameba histolytica.

Figure 2, Table 1, and Figure 3 are forwarded on the next three consecutive pages.

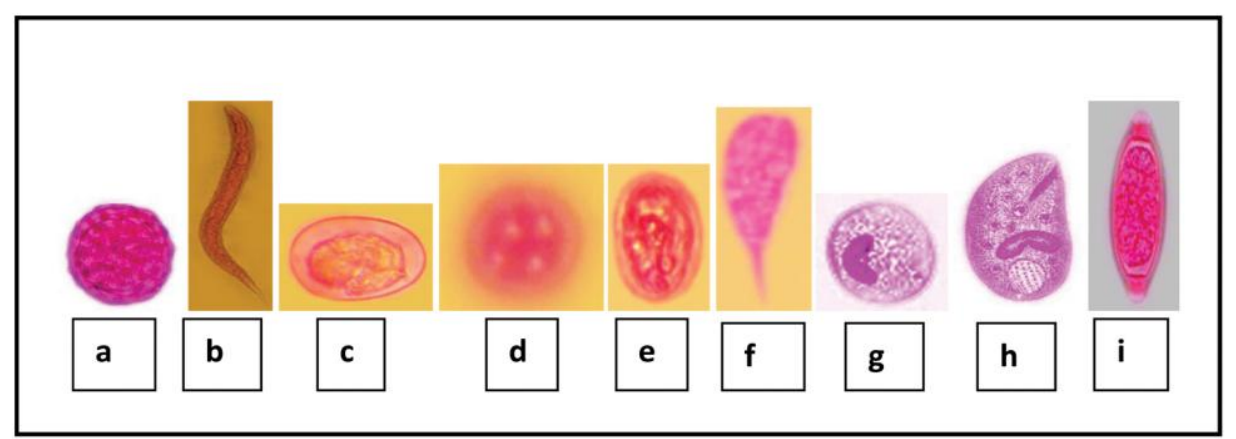

Figure (2) : The list of the most important diagnostic stages (except those of labels: c, f,\& h) of intestinal parasites isolated from fresh stools samples of HIV/AIDS patients in 3 different hospitals, Southern Ethiopia.

(a) Ascaris lumbricoides egg, magn†. X640;

(b) Strongyloides stercoralis rhabditiform larva, magn. X640;

(c) Strongyloides stercoralis egg, magn. X640;

(d) Entameba histolytica cyst, magn. X640;

(e) Giardia lamblia cyst, magn. X1600;

(f) Giardia lamblia trophozoite, X640

(g) Balantidium coli cyst, magn. X640

(h) Balantidium coli trophozoite, magn. X640;

(i) Trichuris trichiura egg, magn. X640.

Each of these six pictures was colored using a computer Adobe Photoshop-CS and transformed from its original magnified size to the resolution of 1200 pixels/inch with the quality of 12 (maximum) and large file compatible with A4 page format.
Egg of Strongyloides stercoralis, and the trophozoites of Giardia lamblia and Balantidium coli are not the most important diagnostic stages, but in this study they were isolated from fresh stools samples. 
Table (1) : The list of human intestinal parasites isolated from fresh stools samples of HIV/AIDS patients under medical care in 3 different hospitals, Southern Ethiopia.

\begin{tabular}{|c|c|c|}
\hline $\begin{array}{l}\text { Total sample size of } \\
\text { HIVIAIDS patients } \\
\text { examined for intestinal } \\
\text { parasites }\end{array}$ & $\begin{array}{l}\text { Intestinal parasitic } \\
\text { species identified in } \\
\text { HIVIAIDS patients }\end{array}$ & $\begin{array}{l}\text { Total number of } \\
\text { HIVIAIDS patients } \\
\text { positive for the } \\
\text { arrowing parasite }\end{array}$ \\
\hline 710 & $\begin{array}{l}\text { 1. Ascaris lumbricoides } \\
\text { 2. Strongyloides stercoralis } \\
\text { 3. Entameba histolytica } \\
\text { 4. Giardia lamblia } \\
\text { 5. Balantidium coli } \\
\text { 6. Trichuris trichiura }\end{array}$ & $\begin{aligned} \longrightarrow & 74(10.42 \%)^{\ddagger} \\
\longrightarrow & 45(6.34 \%) \\
\longrightarrow & 43(6.10 \%) \\
\longrightarrow & 25(3.52 \%) \\
\longrightarrow & 19(2.68 \%) \\
\longrightarrow & 1(0.14 \%)\end{aligned}$ \\
\hline
\end{tabular}

₹The percentile quantity in parenthesis adjacent to the value that meant "total number of HIV/AIDS patients positive for the arrowing parasite:" represented the infection rate of the intestinal parasitic species in the preceding column but in the same row.

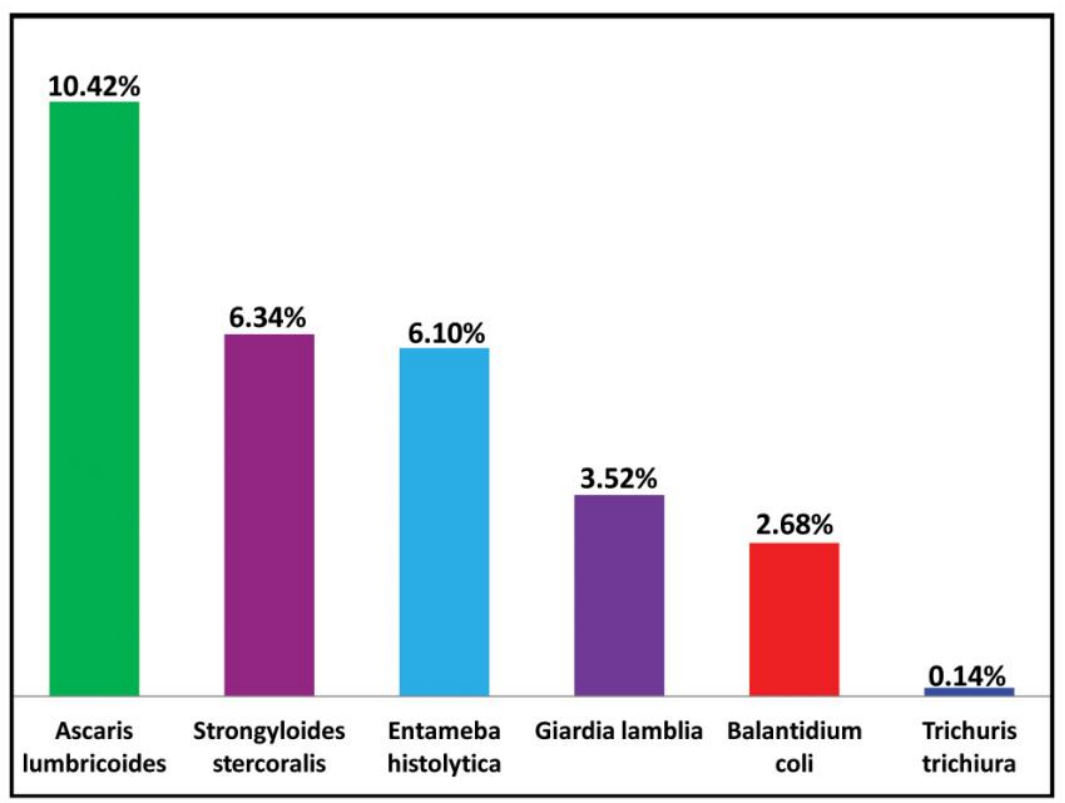

Figure (3) : The Statistic of Histogram, demonstrating the infection rates of intestinal parasites in the population of HIV/AIDS patients in 3 different hospitals, Southern Ethiopia.

\section{DISCUSSION}

Out of 710 HIV/AIDS patients examined for the suspected harmful intestinal parasites, 196 patients were found to be positive. This meant that the infection rate of intestinal parasites in the population of HIV/AIDS patients of the 3 different hospitals is: $\frac{196}{710} \times 100=27.6 \%$

One of the HIV/AIDs patients in one of the 3 hospitals has died in a horrifying situation because of an obvious failure of the patient herself to follow the advice of medical care to maintain her safe and alive. She was advised to come by the end of every one month to the AntiRetroviral Therapy center of the hospital for medical check in order to avoid any harmfully opportunistic infection or illness. However, she stopped coming to the anti-retroviral therapy center of the hospital, i.e., she stopped being treated with Ethiopian Anti-Retroviral Therapy 
Guidelines adopted from WHO Guidelines which involve the administration of CD4 to increase (boost) the immunity of the HIV/AIDS patients. After abandoning attending the services of medical care and advice for six months, she came to the anti-retroviral therapy center of the hospital when she was in the process of dying. At that moment her body was left with skeleton and watery diarrhea (not different from urine). It was at that time (7 March 2014), fresh stools sample of this very patient was taken and examined in which the causative agents of the watery diarrhea were identified to be Balantidium coli and Trichuris trichiura. Curative treatments of the best choices were given, battling to save/rescue her life. However, in spite of all those attempts she died after a while.

Another 13 years old male HIV/AIDS patient was found to be challenged with watery diarrhea. His fresh stools sample (watery diarrhea) was examined and the causative agents of the challenge were verified to be Entameba histolytica and Balantidium coli. The child recovered from this double intestinal parasitic infection via the curative treatment as he was not late with the opportunistic infection and because he was punctual in attending the service of the medical care provided by anti-retroviral therapy division of the hospital.

The list of intestinal parasites isolated from fresh stools samples of HIV/AIDS patients in this study consisted of: A. lumbricoides, $S$. stercoralis, E. histolytica, G. lamblia, B. coli, and $T$. trichiura. Among these, the most dangerous opportunistic parasite to cause lethal risk to HIV/AIDS patients is S. stercoralis if there is failure and interruption in attending the services of medical care according to the recommended safety time intervals. The infection rate of each of the six species of parasites investigated in this study is far less than that in the population of student children of elementary schools (verified and reported herebefore by the researcher of this study project) at Dilla Town and its peripheral villages [36]. Some of the suspected opportunistic intestinal parasites such as Cryptosporidium parvum, Cyclospora cayentanensis, Toxoplasma gondii, Isospora belli and the symptom of explosive watery diarrhea they cause did not appear in the HIV/AIDS patients examined. Hookworms and Schistosoma mansoni are endemic in this region where HIV/AIDS patients tested resided [36]; however, these helminths are not found in the HIV/AIDS patients of this project. One of the major reasons for why:

- These suspected protozoan and helminth intestinal parasites (Cryptosporidium parvum, Cyclospora cayentanensis, Toxoplasma gondii, Isospora belli, hookworms and Schistosoma mansoni) are not found in the HIV/AIDS patients examined,

- The infection rate of each of the six species of parasites investigated in the patients of this study is far lower than that of schools children, and

- The number of different species of parasites harbored in a single person with respect to multiple infection was greater in schools children (5 different species of parasites in a person) than in this study of HIV/AIDS patients (only 2 different species of parasites in a person) must be the protective effect of Anti-Retroviral Therapy that included the administration of CD4 given in the care taker hospitals.

Healthy in taking of mixed diet against weight loss of HIV/AIDS patients was an important component of the medical care and advice offered by care provider health professionals. Based on this, in each of the 3 hospitals the body weight of every HIV/AIDS patient was recorded in every safety time interval in order to take action to increase body weight of the client to normal level by eating more food (either by eating larger portions and/or eating meals more frequently, using a variety of foods) when weight loss was being observed [37].

Getting the stools samples of HIV/AIDS patients examined for opportunist intestinal parasites by experienced parasitologists/medical laboratory experts is very important and useful in giving feedback to care provider physicians for their better patient management so as to avoid fatality.

In conclusion, HIV/AIDS patients must be punctual to the preplanned safety time intervals to attend the services provided by public health institutions. The safety time interval is so named because it is the length of time during which it cannot be late or difficult to treat and get the patient cured from any onset of opportunistic infection if it has happened. It is the recommended segment of duration for medical checkup of the HIV/AIDS patient; example, an interval of one month. This time interval is very important because an opportunistic infection can be cured before it is late and out of control for medication, but reinfection with the same 
opportunistic parasite or with others is possible in each of the following successive safety time intervals. Therefore, the subsequently successive safety time intervals that are estimated and approved by health professionals must be attended continuously by HIV/AIDS patients without interruption to utilize the services of medical care in order to avoid/neutralize the potential opportunistic infections and reinfections. The length of safety time interval is variable and is decisively determined by the physician, who is assigned to take care of the HIV-infected patient, based on the degree of severity in health status of the client. Finally, based on what has been spectacularly observed in this study, the following truth can be stated. If an HIV-infected person who is under medical care fails to attend continuously all the services given (in safety time intervals) by health professionals, he/she must be aware of the fact that fulminant death due to HIV infection can turn to be true soon. On the other hand, the safety \& well-being of those HIV-infected patients who attend all the medical services and advices provided by clinical experts is not different from that of HIV-noninfected individuals without any trace of exaggeration.

\section{Conflict of interest}

I confirm that I don't have any competitive conflict of interest with any body.

\section{Financial support}

The financial support to cover the cost of this study project was given by the Research \& Dissemination Office of Dilla University.

\section{Ethics}

Ethical permission/clearance to perform the research work to contribute to the well-being of HIV/AIDS patients was obtained from Dilla University, the Office of Gedeo-Zone Administration, and the Directors of the hospitals involved in the study.

\section{Acknowledgements}

I am very much thankful to Dilla University for its providing me with the necessary fund to cover the cost of this study project and writing the letters of cooperation or ethical permission to the Directors of the 3 different hospitals involved in the study executed. I am very grateful indeed to Mr. Mohamed Kedir, Focal Person in the AntiRetroviral Therapy (ART) Department, Dilla University, Teaching and Referral Hospital, for his valid professional assistance and making his HIV/AIDS patients motivated participators in giving samples during my data collection. I am also deeply thankful to the health professionals who provide HIV/AIDS patients with the services of medical care in Yirgalem General Hospital and Yirgacheffe Health Center, for their all-rounded cooperation in the process of fresh stools samples taking from their patients.

\section{REFERENCES}

1. Silva CV, Ferreira MS, Borges AS, Costa-Cruz JM. Intestinal parasitic infectionsin HIV/AIDS patients: Experience at a teaching hospital in central Brazil. J Infect Dis 2005; 37(3): 211-5.

2. Kurniawan A, Karyadi T, Dwintasari SW, Sari IP, Yunihastuti E, Djauzi S, Smith HV. Intestinal parasitic infections in HIV/AIDS patients presenting with diarrhea in Jakarta, Indonesia. Trans $R$ Soc Trop Med Hyg 2009; 103(9): 892-8.

3. Pavie J, Menotti J, Porcher R, Donay JL, Gallien S, Sarfati $\mathrm{C}$ et al. Prevalence of opportunistic intestinal parasitic infections among HIV-infected patients with low CD4 cells counts in France in the combination antiretroviral therapyera.Int $J$ Infect Dis 2012; 16(9): e677-9.

4. Wiwanitkit V. Intestinal parasite infestationin HIVinfected patients. Curr HIV Res 2006; 4(1): 87-96.

5. Parboune P. Intestinal parasitic infections in HIVinfected patients, Lao People's Democratic Republic. PLOS 2014; 9(3): e91452.

6. Lindo JF, Dubon JM, Ager AL, Gourville EM, Solo-Gabriele $\mathrm{H}$, Klaskala $\mathrm{WL}$ et al. Intestinal parasitic infections in human immunodeficiency virus (HIV)-positive and HIV-negative individuals in San Pedro Sula, Honuras. Am J Trop Med Hyg 1998; 58(4): 431-5.

7. Tian L, Wang T, Lv S, Wang F, Guo J, Yin X et al. $\mathrm{HIV}$ and intestinal parasite co-infections among a Chinese population: an immunological profile. Infect Dis Poverty 2013; 2:18. Available from: http://www.idpjournal.com/content/2/1/18.

8. Yahaya A, Tyav B, Imam TS. Prevalence of intestinal parasitic infections among HIV/AIDS out- patients attending Wudil General Hospital, Wudil, Kano State, Nigeria.Int J Nov Drug Delv Tech 2013; 3(2): 17-21.

9. Teklemariam Z, Abate D, Mitiku H, Dessie Y. Prevalence of intestinal parasitic infections among HIV positive persons who are naïve and on antiretroviral treatmentin Hiwot Fana Specialized University Hospital, Eastern Ethiopia. AIDS 2013; 2013(2013): 6 pages. Available from: http: //dx.doi.org/10.1155/2013/324329

10. Nkenfou CN, Nana CT, Payne VK. Intestinal parasitic infections in $\mathrm{HIV}$-infected and noninfected patients in a low HIV prevalence region, West-Cameroon. PLOS 2013; doi: 10.1371/ journal.pone.0057914. 
11.KulkarniSV, Kairon R, Sane SS, Padmawar PS, Kale VA, Thakar MR et al. Opportunistic parasitic infections in HIV/AIDS patients presenting with diarrhea by the level of immune suppression. Indian J Med Res 2009; 130: 63-6.

12. Assefa S, Erko B, Medhin G, Assefa Z, Shimelis $T$. Intestinal parasitic infectionsin relation to HIV/AIDS status, diarrhea and CD4 T-cell count. BMC Infect Dis 2009; 9: Available from: http: //www.biomedcentral.com/1471-2334/9/155

13. Wiwanitkit V. Intestinal parasitic infections in Thai HIV-infected patients with different immunity status. BMC Gastroenterol 2001; 1(3): Available from:http://www.biomedcentral.com/1471-230x/1/3

14. Mohandas K, Sehgal R, Sud A, Malla N. Prevalence of intestinal parasitic pathogens in HIV- seropositive individuals in Northern India. Jpn J Infect Dis 2002; 55: 83-4.

15. Cimerman S, Cimerman B, Lewi DS. Prevalence of intestinal parasitic infections in patients with acquired immunodeficiency syndrome in Brazil. Int J Infect Dis 1999; 3(4): 203-6.

16. Guk S, Seo M, Park Y, Oh M, Choe K, Kim J et al. Parasitic infections in HIV-infected patients who visited Seoul National University Hospital during the period 1995-2003. Korean J Parasitol 2005; 43(1): 1-5.

17. Hailemariam G, Kassu A, Abate E, Damte D, Mekonnen E, Ota F. Intestinal parasitic infections in HIV/AIDS and HIV seropositive individuals in a Teaching Hospital, Ethiopia. Jpn J Infect Dis 2004; 57: 41-3.

18. Mayer KH, Karp CL, Auwaerter PG. Coinfection with HIV and tropical infectious diseasesII. helminthic, fungal, bacterial, and viral pathogens. Clin Infect Dis 2007; 45(9): 1214-20.

19. Nissapatorn V, Sawangjaroen N. Parasitic infection in HIV-infected individuals: diagnostic and therapeutic challenges. Indian J Med Res 2011; 134: 878-97.

20. Getaneh A, Medhin G, Shimelis T. Cryptosporidium and Strongyloides stercoralis infections among people with and without HIV infection and efficiency of diagnostic methods for Strongyloides in Yirgalem Hospital, Southern Ethiopia. Bmc Res Notes 2010; 3: 90 doi:10.1186/1756-0500-3-90.

21. Bollela VR, Feliciano C, Teixeira AC, Junqueira ACR, Rossi MA. Fulminant gastrointestinal hemorrhage due to Strongyloides stercoralis hyperinfection in an AIDS patient. Rev Soc Bras Med Trop 2013; 46(1): Available from: http: //dx.doi.org/10.1590/0037-868215522013.

22. Rosiris CJ, Isabel HC, Orlando U, Javier P, Mario R, Norka B. Balantidium coli in an HIV-infected patient with chronic diarrhea. AIDS 2003; 17(6): 941-2.

23. Chen Y,Hang Y, Yang B, Oi T, Lu H, Cheng X et al. Seroprevalence of Entameba histolytica infection in HIV-infected patients in China. Am J Trop Med Hyg 2007; 77(5): 825-8.
24. Asma I, Johari S, Sim BLH, Lim YAL. How common is intestinal parasitism in HIV-infected patients in Malaysia? Trop Biomed 2011; 28(2): 400-10.

25. Tian L, Chen J, Wang T, Cheng G, Steinmann P, Wang F et al. Co-infection of HIV and intestinal parasites in rural area of China. Parasites \& Vectors 2012;5:36 doi:10.1186/1756-3305-5-36.Available from: http: //www.parasitesandvectors.com/ content $/ 5 / 1 / 36$

26. Akinbo FO, Okaka CE, Omoregie R. Prevalence of intestinal parasitic infections among HIV patients in Benin City, Nigeria. Libyan J Med 2010; 5: doi: 10.3402/ljm.v5i0.5506

27. Lau SKP, Woo PCY, Yuen Y. Ascaris-induced eosinophilic pneumonitis in an HIV-infected patient. J Clin Pathol 2007; 60(2): 202-3.

28. Feitosa G, Bandeira AC, Sampaio DP, Badaro R, Brites C. High prevalence of giardiasis and strongyloidiasis among HIV-infected patients in Bahia, Brazil. Braz J Infect Dis 2001;5(6):339-44.

29. Hosseinipour MC, Napravnik S, Joaki G, Gama S, Mbeye N, Banda B et al. HIV and parasitic infections and the effect of treatment among adult outpatients in Malawi. J Infect Dis 2007; 195(9):1278-82.

30. Talaat KR, Kumarasamy N, Swaminathan S, Gopinath R, Nutman TB. Filarial/HIV-coinfection in Urban Southern India. Am J Trop Med Hyg 2008; 79(4): 558-60.

31. Range N, Magnussen P, Mugomela A, Malenganisho W, Changalucha J, Temu MM et al. HIV and parasitic co-infections in tuberculosis patients: a cross-sectional study in Mwanza, Tanzania. Ann Trop Med Parasitol 2007; 101(4): 343-51.

32. Kjetland EF, Ndhlovu PD, Gomo E,Mduluza T, Midzi N, Gwanzura L et al. Association between genital schistosomiasis and HIV in rural Zimbabwean women. AIDS 2006; 20(4): 593-600.

33. Secor WE. The effect of schistosomiasis on HIV/AIDS infection, progression and transmission. Curr Opin HIVAids 2012; 7(3): 254-9.

34. Sadlier CM, Brown A, Lambert JS, Sheehan G, Mallon PWG. Seroprevalence of schistosomiasis and Strongyloides infection in HIV-infected patients from endemic areas attending a European infectious diseases clinic. AIDS Res Therapy 2013; 10: 23. doi: 10.1186/1742-6405-10-23

35. Jourdan PM, Holmen SD, Gundersen SG, Roald $\mathrm{B}$, Kjetland EF. HIV target cells in Schistosoma haematobium-infected female genital mucosa. Am J Trop Med Hyg 2011; 85(6): 1060-64.

36. Feleke E. Intestinal parasitic infections in elementary schools children at Dilla Town and its peripheral villages. Afro-Egypt J Infect Endem Dis 2014; 4(2): 88-95.

37. NAM. Healthy eating. HIV Glasgow 2011; 2707596: 3 pages. Available from: http://www.nhs. uk/livewell/goodfood. 
Peer reviewer: Agnes Kurniawan, AKIND Professor of Parasitology Faculty of Medicine, University of Indonesia, Jakarta, Indonesia, Mohieddin Elbaboly, Professor of Medical Parasitology, Faculty of Medicine, Zagazig
University, Egypt.

Editor: Tarik I Zaher, Professor of Tropical Medicine and Hepatogastroenterology, Faculty of Medicine, Zagazig University, Egypt 